\title{
THE ROAD RESEARCH LABORATORY OPEN DAYS
}

$\mathrm{O}^{\mathrm{n}}$ PEN days were held at the Road Research Laboratory on May 15 and 16, when the work of the Materials and Construction Division at Harmondsworth and that of the Traffic and Safety Division at Langley were visited by some 2,000 highway engineers, manufacturers of contractors' plant, police, road-safety officials and others in a position to make use of the results of the Laboratory's investigations.

Among the exhibits were methods devised at the Laboratory for testing motor-cycle crash helmets for protecting the wearer against fracture of the skull or concussion, and for ensuring that the peak of the helmet is not so flexible that it will flap in a fastmoving airstream nor so stiff as to present a hazard in the event of a crash. The British Standards Institution uses these tests to maintain the high quality of helmets bearing the 'kite' mark. Another display showed the technique for investigating injuries due to 'crashes'. With the co-operation of the police forces in the areas of Slough, Windsor and Staines, a team from the Laboratory proceeds to the scene of each accident and collects data on the circumstances, and on damage to the vehicles and injuries to their occupants or to other road users. The data may include pairs of stereo-photographs from which an accurate record to scale of skid marks and other visible evidence of events immediately prior to a collision can be obtained with plotting equipment. The many photographs shown illustrated the importance of the failure of vehicle seats or fixtures in aggravating injuries sustained by occupants of a car, and the importance of a yielding rather than a rigid design of steering wheel and column if a driver is to escape serious chest injuries in a collision.

Another group of exhibits consisting simply of defective parts taken from cars was frightening in its implications on safety--it included a steering-wheel assembly in which the play was a quarter of the movement from lock to lock. During the open days, visitors were invited to have their cars tested by the Laboratory's equipment; a common defect found was misaligned headlamps. Of exhibits concerned with vehicles, that which attracted most attention was a short film showing how loss of control can occur when braking and how it can be overcome by using the Maxaret anti-skid device; this releases the pressure in the hydraulic braking system of any wheel of a car as soon as it begins to skid during emergency braking. The car in the film was braked heavily from 65 miles per hour and was manceuvred successfully around obstacles without loss of control. Another striking set of exhibits was a series of toughened glass windscreens which had been caused to crack into the characteristic mosaic by hitting them with a centre punch; a screen made a few years ago which had cracked into a mosaic of forty or more particles per square inch was difficult to see through, but one made to the present British Standard of twenty particles per square inch would provide a fairly clear view of the road ahead.

There were a number of exhibits illustrating the use of statisties (reported by the police and others) in revealing the importance of the various factorsroad, vehicle and human-which affect the problem of accidents. For example, these statistics show that one type of accident to which young children are particularly prone could be reduced by fitting an ingenious safety device which consists of a strip of mirror fixed in front of the cab of a battery-driven electric vehicle of the type used for 'milk rounds'. A glance in the mirror before he moves off will enable the driver to detect the presence of a very small child playing on the road immediately in front of his vehicle.

Another group of exhibits was concerned with making roads and air-strips more resistant to skidding. This comprised a car equipped with a 'fifth wheel' for routine tests at normal speeds, a car and 'braking-force' trailer for testing wet airfield runways at speeds up to 100 miles per hour, and the Laboratory's portable 'skid-resistance' tester: this is a simple pendulum device under development for use by highway authorities for detecting slippery roads.

The Laboratory's apparatus for measuring the reflecting power of a road surface was also on show : this constant is needed by illuminating engineers in determining the capacity of the road surface to form the bright patches on which the lighting engineer relies for effective lighting of streets. Pedestrians are mainly seen in silhouette against the bright background of road surface and not by direct illumination.

The traffic exhibit was notable as showing the large amount of data on the way Great Britain's roads are handling traffic. Examples were included of apparatus now available commercially for use by highway authorities for recording the flow and speed of the traffic on their roads. A new feature was the inclusion of teleprinter devices for recording traffic speeds automatically.

A model road was used to illustrate the Laboratory's work in making road signs easier to read; it showed that for signs of the same area and cost, taking the distance at which the British-type sign with 4-in. letters could be read as unity, this distance was half as much again for the Continental 'map'-type sign with 5 -in. letters and was doubled for the United States 'list'-type sign with 6 -in. letters.

Several of the exhibits were concerned with the development of machinery in road construction ; thus in one large hangar type of building covering a number of pits filled with different soils, measurements were in progress of the depth of the compacted layer and the density of compaction achieved by vibrating rollers and vibrating plate devices : this investigation is designed to supplement the information on soil compaction given in the Laboratory's text-book, "Soil Mechanics for Road Engineers". In another hangar, experiments were in progress with a machine which was pulverizing a heavy clay with an action resembling a milling cutter as it moved over it. The problem here was to shred the soil very finely so that it would mix satisfactorily with cement, the resulting 'soil cement' being compacted to give a road base of high bearing power. Another exhibit, dealing with the problem of laying a concrete road free from 
undulations so that vehicles could ride over it very smoothly, used a working model to demonstrate the advantage of having a long wheel-base to the machine carrying the finishing screed.

In another exhibit samples of road-stones set in cement mortar and forming the tyre of a large wheel were being polished by the rubbing action of the tread of a smooth rubber tyre of another wheel, water and a fine abrasive being pumped on to the tyre. The degree of roughness remaining on the stones after polishing was then assessed in terms of the energy abstracted from a pendulum used to sweep a rubber pad over the samples of wetted stones. Use of this test would ensure that road-stones that polish easily are not used on sites, such as roundabouts on main roads, where it is desirable to maintain a high degree of resistance to skidding for safety in wet weather.

Another group of exhibits gave details of the Laboratory's full-scale road experiments concerned with 'pavement design', that is, the determination of the most economical type and thickness of road construction for use in a particular locality bearing in mind the road-stones and sands available, the bearing power of the subsoils over which the roads are built and the weight and intensity of the traffic to be met with ; here a large-scale plan gave details of the 'step' experiment at Alconbury on road $A 1$, where a two-mile stretch consists of sections of different road materials, each laid to a range of thicknesses. Instruments have been installed in each section and these record the pressures and deformations in the road structure and in the subsoil: from these and other studies it should be possible to assess the relative suitability of the various materials involved. In connexion with this type of experiment it is vital to know the weights of the different vehicles using the road; these are determined by a device which, for the purpose of the exhibition, was shown weighing the fast-moving traffic on the Colnbrook By-pass outside the Harmondsworth Laboratory. The device consists of a steel table, let flush into the road and carrying resistance strain gauges on the four legs: the system causes a spot of light to be deflected across a row of photo-sensitive elements actuating counters, the number of counters triggered off by each vehicle being a measure of the load. Another piece of work being done on this problem of 'pavement design' was exemplified by equipment adjacent to a test-track in the Laboratory grounds at Harmondsworth. Here a heavy vehicle was run over a group of sections of road of different compositions, and piezo-electric gauges in the underlying soil recorded the pressure exerted through each material, thus enabling its ability to spread the traffic loads to be determined.

Several exhibits were concerned with laboratory investigations. Thus a Thoma blood-count slide, modified to act as a micro-viscometer, was being used to determine the viscosity of the bitumen in the extreme surface layers of asphalts. This viscosity increases due to oxidation of the bitumen, but is decreased by the absorption of oil dropped from vehicles. To maintain a high resistance to skidding, an increased viscosity of the bitumen is desirable so that any bitumen in the surface is worn away by traffic so as to expose the sand or other fine aggregate texture.

One problem of immediate practical importance was concerned with determining the best surfacing for the roadway of the new Forth and Severn bridges. Trials on actual sections of the proposed bridge decks have suggested that $1 \frac{1}{2}$ in. of mastic asphalt sealed at the edges with rubber/bitumen will hold well to the steel decking and give long service under heavy traffic.

A pictorial display showed something of the work of the Colonial Section.

T. LONSDALE

\section{SCIENCE IN THE USE OF COAL}

A CONFERENCE on "Science in the Use of Coal" $A$ was convened at the University of Sheffield during April 15-17 by the Institute of Fuel to provide an opportunity for coal scientists to discuss their work with industrialists. Each session began with an authoritative survey of work already published and an appreciation of current industrial problems.

\section{Physics and Chemistry of Coal}

In reviewing the properties of British coal seams, A. M. Wandless laid emphasis on the heterogeneity of coal and the great commercial importance of coals of low rank. In the second paper, L. Horton surveyed the chemical constitution of coal, with particular reference to oxidation, functional groups and solvent extraction. I. G. C. Dryden extended this discussion, referring, inter alia, to statistical structural analysis and physical structure. These valuable summaries not only provided a foundation for the subsequent proceedings, but also focused attention on what remains to be done and the most likely fields of application. For example, Dryden said that carbonization offers the most immediate application for coal science, while Wandless made clear that further work applicable to the use of small coal of low rank and on sulphur and other mineral constituents is particularly necessary.

During the session it became clear that there is now available sufficient information about the aromatic skeleton in coal and the nature of nonaromatic and oxygen groups to limit closely the possible views on the structure of coal. P. B. Hirsch interpreted the X-ray evidence for vitrains containing up to 90 per cent carbon in terms of ordered layers containing a few condensed aromatic rings, the layers being cross-linked to form larger units. This view conforms with the chemical evidence. P. H. Given and M. E. Peover provided evidence from controlled potential electrolysis for the presence of carbonyl groups conjugated with the ring system, previously suggested from consideration of the behaviour of the $1,600-\mathrm{cm}^{-1}$ band in infra-red spectra. Attempts to reduce the aromatic systems led P. H. Given, V. Lupton and M. E. Peover to suggest that this process is resisted in coals of low rank owing to a high degree of cross-linkage. J. K. Brown et al. demonstrated by purely chemical means the presence of aliphatic groups, showing also that halogenation and nitration may prove efficient in introducing desired functional groups into coals. Photochemical studies by R. Bent and J. K. Brown 